\title{
The Role of MR Enterography in Crohn's Disease
}

\section{Crohn Hastalığında MR Enterografısinin Rolü}

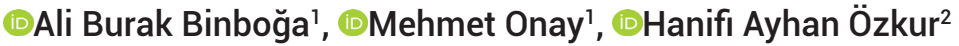 \\ 'Dr.Ersin Arslan Training and Research Hospital, Department of Radiology, Gaziantep, Turkey \\ ${ }^{2}$ SANKO University Faculty of Medicine, Department of Radiology, Gaziantep, Turkey \\ Copyright@Author(s) - Available online at www.dergipark.org.tr/tr/pub/medr \\ Content of this journal is licensed under a Creative Commons Attribution-NonCommercial 4.0 International License.
}

\begin{abstract}
Aim: The aim of this study was to investigate the efficacy of magnetic resonance enterography (MRE) in the diagnosis and follow-up of Crohn's Disease.

Material and Methot: Between November 2013 and April 2014, patients who were MRE examinations for a preliminary or definitive diagnosis of Crohn's Disease were reviewed retrospectively. MRE imaging of the patients was performed on an 8-channel 1.5 Tesla MRI device. Primary and secondary MRE results and contrast enhancement patterns of active and chronic inflammation of Crohn's disease in jejunum, ileum, terminal ileum, and colon segments were evaluated by two radiologists.

Results: The results consistent with Crohn's Disease were detected in 19 ( 10 male, 9 female) of 42 patients (24 male, 18 female, mean age was 40.64 years, min-max: 20-69, SD \pm 14.27 ). Signs of active inflammation which were intestinal wall thickening, T2 signal reduction, and pathological mucosal contrast enhancement were observed in 19 patients (26 intestinal segments). Active inflammation findings were most common in the terminal ileum, with $16(61.5 \%)$, followed by 5 (19.2\%) in the ascending colon, $2(7.6 \%)$ in the jejunum, $2(7.6 \%)$ in the nonterminal ileum, and $1(3.8 \%)$ in the sigmoid colon. Chronic inflammation findings such as intestinal stenosis (18 intestinal segments), submucosal fat deposition (16 intestinal segments), and prestenotic dilatation (13 intestinal segments) were observed in 13 patients. There was an ileosigmoid fistula in 1 patient, enterovesical fistula in 1 patient, and enterocutaneous fistula in 1 patient.

Conclusion: MRE is an appropriate diagnostic method without ionizing radiation, which can be used to detect the stage of inflammation (active or chronic) in the diseased intestinal segments in the diagnosis and follow-up of Crohn's disease.
\end{abstract}

Keywords: Crohn's disease, MR enterography, inflammatory bowel disease

Öz

Amaç: Bu çalışmanın amacı, Crohn hastalığı tanı ve takibinde manyetik rezonans enterografisinin (MRE) etkinliğini araştırmaktır.

Materyal ve Metot: Kasım 2013 ile Nisan 2014 tarihleri arasında Crohn hastalığı ön veya kesin tanısı için MRE incelemesi yapılan hastalar geriye dönük olarak tarandı. Hastaların MRE görüntülemesi 8 kanallı 1.5 Tesla MRI cihazında yapıldı. Crohn hastalığının jejunum, ileum, terminal ileum ve kolon segmentlerindeki aktif ve kronik inflamasyonunun primer ve sekonder MRE sonuçları ve kontrast artış paternleri iki radyolog tarafından değerlendirildi.

Bulgular. 42 hastanın (24 erkek, 18 kadın, ortalama yaş 40.64, min-maks: 20-69, SD \pm 14.27 ) 19'unda (10 erkek, 9 kadın) Crohn Hastalığı ile uyumlu sonuçlar saptandı. 19 hastada (26 bağırsak segmenti) bağırsak duvarı kalınlaşması, T2 sinyal azalması ve patolojik mukozal kontrast artışı gibi aktif inflamasyon belirtileri gözlendi. Aktif inflamasyon bulguları en sık terminal ileumda 16 $(\% 61,5)$ ile ardından $5(\% 19,2)$ çıkan kolonda, $2(\% 7,6)$ jejunum, $2(\% 7,6)$ nonterminal ileum ve $1(\% 3,8)$ sigmoid kolonda. 13 hastada barsak darlığı (18 barsak segmenti), submukozal yağlanma (16 barsak segmenti) ve prestenotik dilatasyon (13 barsak segmenti) gibi kronik inflamasyon bulguları gözlendi. 1 hastada ileosigmoid fistül, 1 hastada enterovezikal fistül ve 1 hastada enterokutan fistül mevcuttu.

Sonuç: MRE, Crohn hastalığının tanı ve takibinde hastalıklı bağırsak segmentlerindeki inflamasyonun (aktif veya kronik) evresini saptamak için kullanılabilecek iyonize radyasyon içermeyen uygun bir tanı yöntemidir.

Anahtar Kelimeler. Crohn hastalığı, MR enterografı, inflamatuar bağırsak hastalığı 


\section{INTRODUCTION}

Conventional radiological methods such as enteroclysis and small bowel passage graph which have been used for years in the radiological diagnosis of small bowel pathologies, provide direct information about the lumen width and function of the small bowel as well as indirect information about the intestinal wall and surrounding tissues (1). Therefore, the use of conventional modalities in combination with cross-sectional imaging methods (computed tomography, CT, magnetic resonance imaging, MRI) for the evaluation of the small bowel is considered to be a complementary step and creates a chance to investigate intra-abdominal complications that may accompany the intestinal disease. However, the success of cross-sectional imaging methods in demonstrating mucosal pathologies is limited (2). Small bowel passage $X$-rays have minimal success in demonstrating all small bowel pathologies, including mucosal lesions (3).

As a result of the advances in CT and MRI technology, the small bowel can be imaged in a very short time and with good quality, and reconstructed images may be obtained after the examination (2). The prerequisite for a good small bowel examination with CT and MRI is to ensure adequate intestinal distension (2). In recent years, CT and MR enteroclysis-enterography (MRE), which are used for small bowel imaging, have emerged as methods that combine the advantages of conventional enteroclysis and cross-sectional imaging in a single examination (4).

We aimed to evaluate the contribution of the MRE method to the radiological diagnosis and follow-up of Crohn's Disease (CD), investigate its advantages and disadvantages, and enable it to be widely used.

\section{MATERIAL AND METHOD}

Our study was carried out upon permission no. 24.02.2014/75 dated 24.02.2014 of the Medical Ethics Committee of Gaziantep University, Faculty of Medicine.

MRE examination was performed in 42 patients who had a preliminary diagnosis of $C D$ or were followed up with the diagnosis of $C D$ and presented to the Department of Gastroenterology between November 2013 and April 2014 in the Department of Radiology of Gaziantep University Faculty of Medicine.

Patients with a known allergy to the drugs to be used, pregnant women, patients with hemodynamic instability, and those who did not accept MRI were not included in the study. All patients were subjected to examination after 12 hours of fasting. Water and Osmolac were used to provide intestinal distension and reduce the absorption of intraluminal fluid through the small bowel lumen. Two hours before the shooting, the patients were given 1500 $\mathrm{ml}$ of drinking water, $250 \mathrm{ml}$ every 10 minutes for one hour. Then, the patients were given a solution prepared by adding $100 \mathrm{ml}$ of Osmolac $(667 \mathrm{mg} / 250 \mathrm{ml}$ lactulose solution) syrup to $1400 \mathrm{ml}$ of drinking water, $250 \mathrm{ml}$ every 10 minutes, $1500 \mathrm{ml}$ in total, for the remaining hour until the shooting time. The patients were administered two ampules of hyoscine-n-butyl bromide (Buscopan, Boehringer Ingelheim) intravenously, $40 \mathrm{mg}$ in total, in 2 doses 20 minutes before and at the beginning of the procedure. Buscopan was given manually by slow infusion over 2 minutes.

The examination was carried out using an 8-channel phased-array body coil on an MRI device with 1.5 Tesla magnet power (Gyroscan Intera, Philips, Holland). The patients were placed in the supine position on the MRI device. Firstly, coronal T2 SSh-TSE (Single Shot Turbo Spin Echo), coronal T1 SPIR (Spectral Presaturation Inversion Recovery), coronal T1 IP (In Phase), axial T1 $I P$, and axial T1 SPIR sequences were obtained, and 10 mg of IV contrast medium was administered as a bolus. Coronal T1 SPIR, coronal T1 IP, axial T1 IP, and axial T1 SPIR sequences were obtained 40 seconds after contrast medium administration. Adverse effects such as nausea, vomiting, allergic reaction, and abdominal pain that may develop against antispasmodic drugs and IVCM administered before and during the examination were assessed. MRE images were evaluated retrospectively by two radiologists in two stages. Small bowel distension results in the first stage were divided into four groups of no distension, poor distension, moderate distension, and optimal distension. In the second stage, during the analysis of MRE images, evaluations were made primarily in terms of focal or diffuse intestinal wall thickening and contrast-enhancement pattern in these foci, the hypervascular appearance of the intestinal mesentery, presence of mesenteric lymphadenopathy, presence of stenosis, and prestenotic dilatation in the intestinal segment, mesenteric adipose tissue proliferation, intraperitoneal fluid, fistula, and abscess. The intestinal wall thickness of more than $3 \mathrm{~mm}$ in distended intestinal segments and a short axis of mesenteric lymph nodes greater than $5 \mathrm{~mm}$ were considered pathological. Linear tracts extending between two epithelial surfaces were considered to be fistulas, and collections with peripheral contrast enhancement were considered to be abscesses.

It was attempted to interpret the activation of the disease based on the form and extent of contrast enhancement of the thickened intestinal wall. While the contrast enhancement pattern where mucosal contrast enhancement was prominent was interpreted in favor of active disease, the presence of stenosis in the intestinal lumen and the hypervascular appearance of adipose tissue adjacent to the involved intestinal segment was interpreted in favor of chronic disease.

\section{RESULTS}

A total of 42 patients, 24 men $(57.14 \%), 18$ women (42.85\%), aged between 20 and 69 years (mean \pm SD: $40.64 \pm 14.27$ ), who had a preliminary diagnosis of $C D$ or were followed up with the diagnosis of $C D$, were included in our study.

Collapsed jejunal loops were observed in 5 (11.9\%) of our cases, 14 (33.3\%) had poor distension, 18 (42.8\%) 
moderate distension, and 5 (11.9\%) optimal distension. 5 $(11.9 \%)$ of our cases had poor distension in the ileal loops, $16(38.1 \%)$ moderate distension, and 21 (50\%) optimal distension.

Pathological wall thickening assessed in favor of CD was found in a total of 26 intestinal segments in 19 (45.2\%) of 42 cases, and all of them had active stage findings. In $13(68.4 \%)$ of these patients, chronic stage findings were observed in a total of $18(69.2 \%)$ intestinal segments, and there were findings consistent with activation. Of the 26 involved intestinal segments, 2 (7.6\%) was jejunum involvement, 2 ( $7.6 \%)$ nonterminal ileum involvement, $16(61.5 \%)$ terminal ileum involvement, $5(19,2 \%)$ the ascending colon involvement, and 1 (3.8\%) sigmoid colon involvement.

All 26 involved intestinal segments had T2 signal reduction and thickening of $3 \mathrm{~mm}$ or more in the wall as well as stratified contrast enhancement consistent with activation Enlargement of lymph nodes, one of the secondary signs of activation, in the region adjacent to 14 intestinal segments, and the comb sign, the hypervascular appearance in mesenteric adipose tissue in 12 intestinal segments were observed. In our 13 patients with chronic stage findings, there was stenosis in the intestinal lumen associated with the chronic stage in a total of 18 bowel segments, and prestenotic dilatation was observed in 13 of them. An increase in adipose tissue adjacent to the involved intestinal segment, which has a chronic stage finding, was observed in 16 intestinal segments. Extraintestinal pathologies were also detected in our patients. There was an ileosigmoid fistula in 1 case, enterovesical fistula in 1 case, and enterocutaneous fistula in 1 case. In addition, abdominal pathologies not related to $C D$ were found in our patients. Hepatomegaly was found in 1 case, uterine myoma in 1 case, accessory spleen in 1 case, and renal cysts in 2 cases. Examples of MR enterography images of our cases are shown in Figures 1-3.
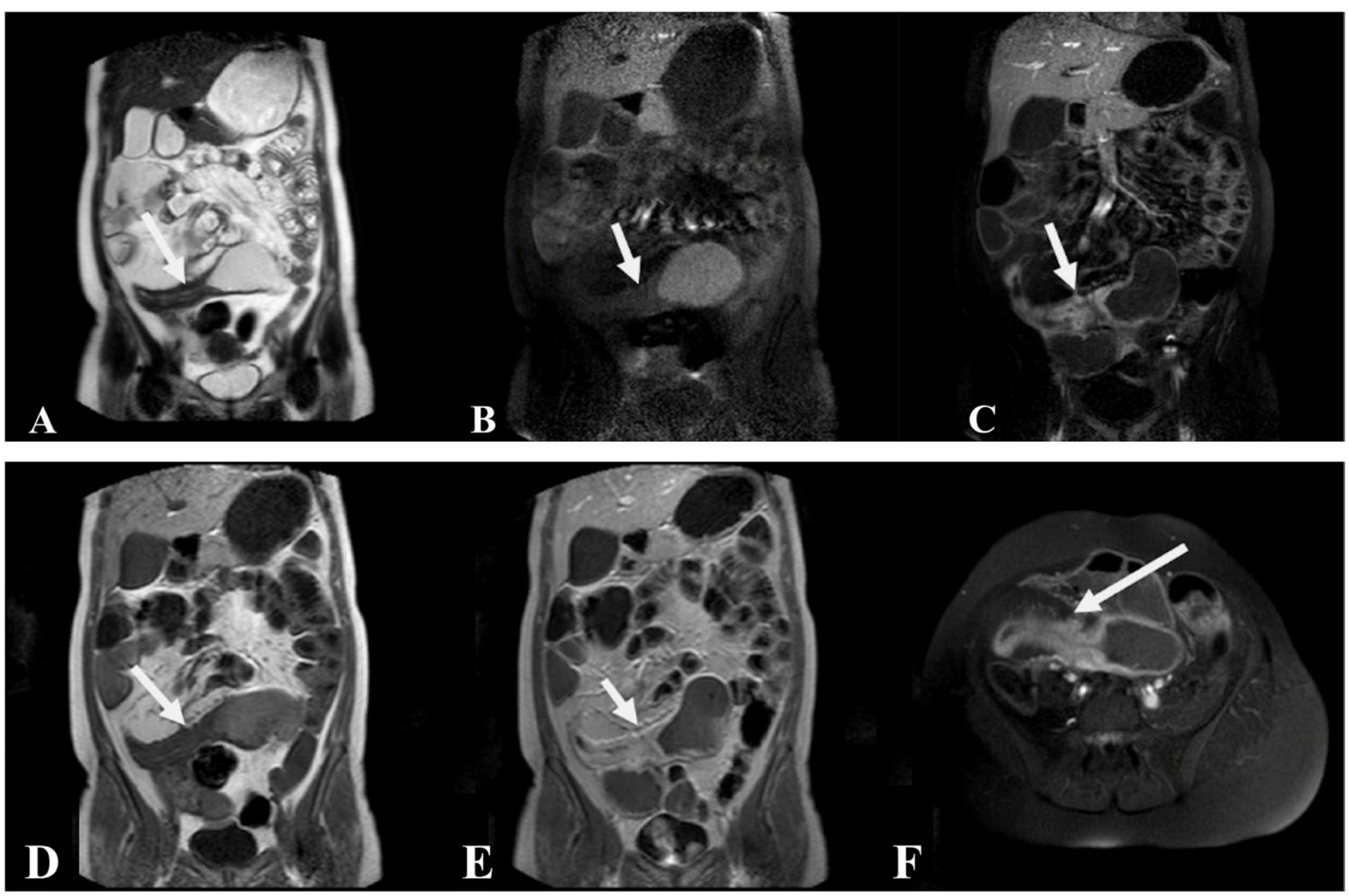

Figure 1. 48-year-old female patient; $(A)$ view of wall thickening, mesenteric adipose tissue increase, stenosis and prestenotic dilatation in the terminal ileum in T2 SSh-TSE sequence, (B-C) coronal view in T1 SPIR pre-/post-contrast sequence of the same region, (D-E) coronal view in T1 IP pre-/post-contrast sequence of the same region, (F) axial view in T1 SPIR post-contrast sequence of the same region. 


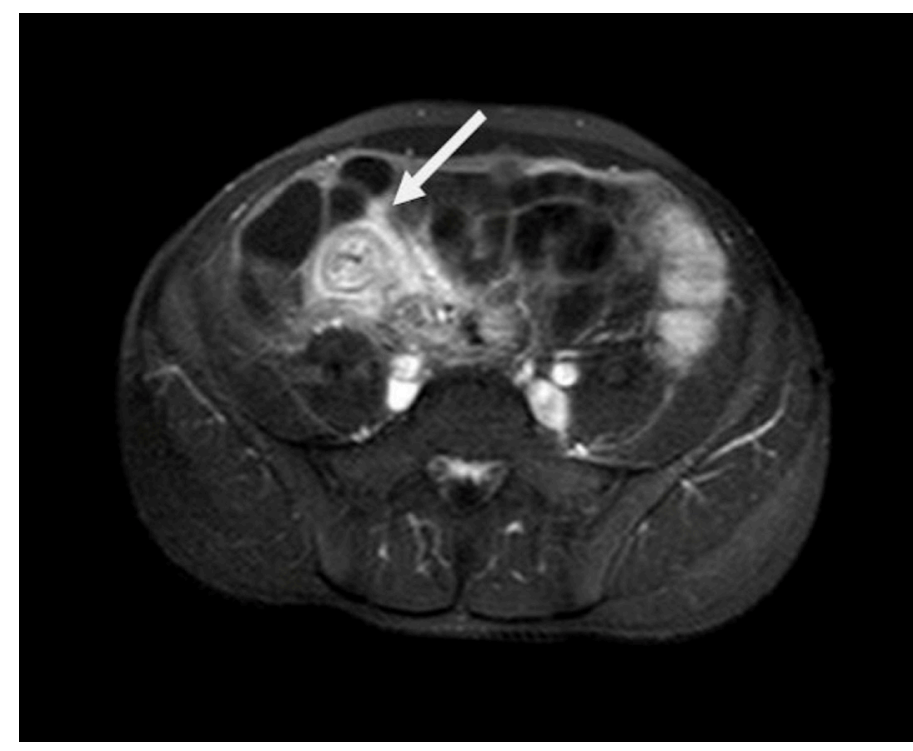

Figure 2. 26-year-old male patient; target sign appearance on the axial view in the T1 SPIR post-contrast sequence

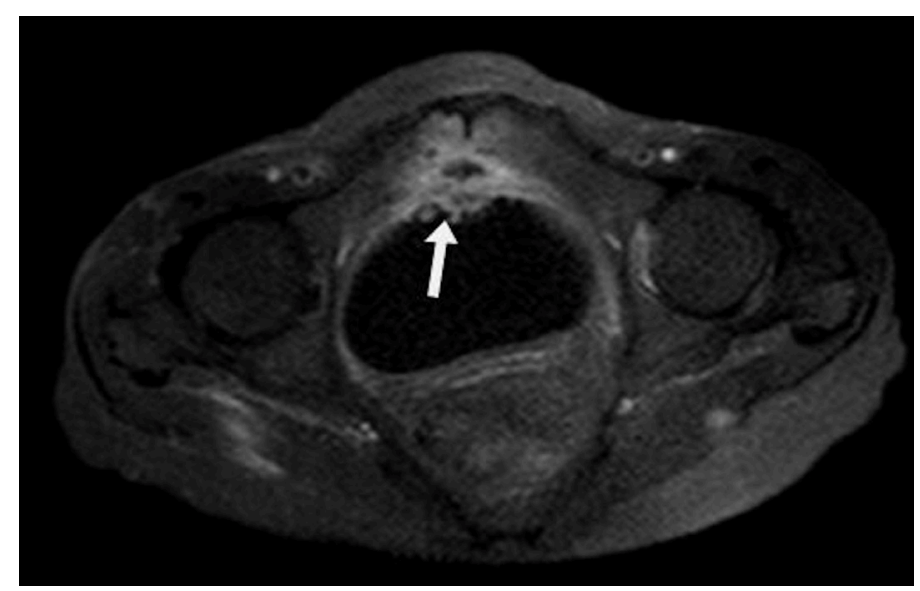

Figure 3. 66-year-old female patient; enterovesical fistula appearance on the axial view in the T1 SPIR post-contrast sequence

\section{DISCUSSION}

$C D$, one of the inflammatory bowel diseases, is characterized by inflammation of the gastrointestinal tract, with granulomatous, non-caseating, transmural, and segmental involvement (5). It usually starts in adulthood and progresses with remissions and relapses (6). Currently, there is no standard method to evaluate CD activity. MRI has been used for diagnostic purposes for CD since many studies have demonstrated its high sensitivity in assessing both disease activity and severity at the terminal ileum level $(7,8)$.

The Vienna Classification, established by an international working group in 1998, enabled CD to be evaluated under three important clinical entities (9). They were age, GIS localization, and disease type. The disease type was also divided into three as non-penetrating-non-stricturing, stricturing, and penetrating (10). Perianal penetration was added to the Vienna Classification as a distinct disease type, as it was thought to have a different prognosis, being modified by the 2005 Montreal Classification (11). Schill et al. (11) found non-penetrating-non-stricturing type in $5 \%$ of the patients, stricturing type in $21 \%$, and penetrating type in $74 \%$ in their study of 76 patients. Our research found non-penetrating-non-stricturing type in $31 \%$, stricturing type in $53 \%$, and penetrating type in $16 \%$ of patients.

Another radiological method used in the evaluation of the small bowel is CT enterography. However, the most crucial problem in CT enterography is ionizing radiation exposure. It is emphasized that radiation and agents used for treatment, especially in young patients, may increase cancer risk with a synergistic effect (12). However, in comparison with MRE, the advantages of CT enterography include the ability to maintain intestinal distension throughout the examination due to its shorter duration, its good spatial resolution, and the ability to obtain highquality multiplanar imaging (13).

As many small bowel diseases are pathologies that appear in the first years of life and should be followed up for years, in recent years, the MRE method has been developed to reduce radiation exposure in the diagnosis and follow-up of $C D$, especially in pediatric patients (14, 15). MRE may also provide information about benign or malignant lesions, polyposis, inflammatory processes such as vasculitis, other diseases of the small bowel such as celiac disease, infectious conditions, systemic sclerosis, intestinal duplications, and mesenteric tumors (16). MRE and MR enteroclysis are very important techniques in the imaging of the small bowel, as they do not contain ionizing radiation. They have high soft-tissue contrast, show extraintestinal pathologies, and obtain reproducible results data in terms of bowel function. In addition, gadolinium, a contrast medium, is preferred because of its safety profile and the ability for real-time imaging (17).

To date, there are no generally accepted techniques in terms of examination parameters and evaluation methods in the preparation of patients who will undergo MRE. Although there is no consensus on the necessity of bowel cleansing before the examination, we recommended 12hour fasting with a liquid and pulp-free food diet. However, we did not use the methods of cleaning the intestines with laxatives.

Optimal distension in the small bowel with oral contrast medium administration in MRE is very important for the efficiency of the examination (18). Adequate intestinal distension for MRE is of great importance for demonstrating pathological wall thickness and pathological contrast enhancement. Many oral contrast media may be used for this purpose. The contrast media are classified according to their T1 and T2 characters. As biphasic oral contrast media appear hypointense in the intestinal lumen on T1weighted images, they reveal the contrast-enhancement between the contrast-enhanced wall and the lumen on T1-weighted images obtained after IV contrast medium (19). Hidalgo et al. (20) used 1.5-2 liters of polyethylene 
glycol solution as an oral contrast medium before the procedure. In our study, water and Osmolac syrup were utilized as a biphasic oral contrast medium in all cases. Osmolac is a readily available and inexpensive agent in our country. Other biphasic agents (methylcellulose, sorbitol) are not easily available and difficult to find in our country. Osmolac increases intestinal secretions and motility by increasing the intra-intestinal osmotic pressure.

One of the important limitations of the MRE is the insufficient intestinal distension, especially in the jejunal loops. Therefore, an oral contrast medium should be administered at an appropriate dose and rate for optimal intestinal distension. However, there may be cases where optimal distension cannot be achieved because gastric emptying time and passage transit time differs in each patient. In our study, drinking water and Osmolac (667 $\mathrm{mg} / 250 \mathrm{ml}$ lactulose solution) syrup were given orally to all cases. The patients were given $1500 \mathrm{ml}$ of water two hours before the shooting, $250 \mathrm{ml}$ every 10 minutes for one hour. Then, the patients were given a solution prepared by adding $100 \mathrm{ml}$ of Osmolac syrup to $1400 \mathrm{ml}$ of drinking water, $250 \mathrm{ml}$ every 10 minutes, $1500 \mathrm{ml}$ in total, for the remaining hour until the shooting time.

As the patient is taken to the MRI unit with a full stomach, the fluid for sustaining the intestinal distension continues to pass from the stomach to the small bowel, and especially jejunum distension can be achieved. In our study, collapsed jejunal loops were observed in 5 $(11.9 \%)$ of the cases, 14 (33.3\%) had poor distension, 18 (42.8\%) moderate distension, and 5 (11.9\%) optimal distension. $5(11.9 \%)$ of our cases had poor distension in the ileal loops, 16 (38.1\%) moderate, and 21 (50\%) optimal distension.

In MRE, IVCM is recommended in addition to a biphasic intraluminal contrast medium. Thus, the contrastenhancement difference between the lumen and the intestinal wall becomes more evident, and the morphology and pathologies of the intestinal segments may be revealed more clearly. In addition, MRE has an important place in the follow-up of patients since pathological contrast enhancement in the intestinal wall is an indicator of mural inflammation. IVCM injection helps reveal active inflammation and detectable masses, especially in IBD (21). In our study, 10 mg of contrast medium was given intravenously as a bolus to all patients. Postcontrast images were taken 40 seconds after IVCM was administered. In this way, pathological intestinal wall thickening and pathological wall contrast enhancement have been optimally imaged. There are also similar studies in the literature.

Another important limitation of MRI in evaluating the small bowel is artifacts due to small bowel movements. It is recommended to administer glucagon or Buscopan to patients to minimize small bowel movements and prevent artifacts that may occur during MRI $(13,22)$. The use of Buscopan is more common in the literature. In our study, we also administered a total of $40 \mathrm{mg}$ of IV Buscopan in two equal doses, 20 minutes before the procedure and at the beginning of the procedure in all cases. Studies in the literature that Buscopan may be used in doses between $10 \mathrm{mg}$ and $40 \mathrm{mg}(20,23)$. Besides being inexpensive and readily available, Buscopan, unlike glucagon, is an antispasmodic that does not affect sugar metabolism (24). However, it is inconvenient to use in benign prostatic hyperplasia, glaucoma, myasthenia gravis, congestive heart failure, or Buscopan allergy (24). Glucagon can be used in these cases. Another thing to consider when giving Buscopan is the injection time. When the injection is performed quickly, it may lead to hypotension, dizziness, dry mouth, and accommodation disorders in the eye due to its anticholinergic effect (25). No adverse effects related to Buscopan were observed in our patients.

Non-contrast T2-weighted images and contrastenhanced fat-suppressed T1-weighted images are critical for MRE in revealing small bowel wall thickening and its cause (13). The upper limit of normal intestinal wall thickness is considered to be $3 \mathrm{~mm}(26)$. Onay et al. (27) observed that the most frequent MRE change in $\mathrm{CD}$ was mural thickening in the intestinal wall. The reason for the increase in wall thickness may be inflammatory events as well as malignant diseases. Stratified contrast enhancement in the segment with increased wall thickness is significant for the classical target sign appearance and excludes malignant wall thickening (26). In addition, having the thickening in the long segment (except lymphoma) suggests benign conditions (28). While the striations in the perienteric adipose tissue observed adjacent to the wall thickening point an acute inflammatory event, the normal presence of the adipose tissue in the presence of thickening reduces the suspicion of an acute inflammatory event (13). Wall thickening in IBD may be seen in the acute phase as well as in the chronic phase (29). On contrastenhanced images, intestinal wall contrast enhancement varies in chronic and acute stages. In the chronic stage compared to the acute stage, the thickening of the intestinal wall continues while the contrast enhancement gradually decreases and becomes almost equal to the normal intestinal loops (29). In MRE, it was determined that there was an increase in the intestinal wall thickness in the active stage. Target sign appearance, which is an indicator of active inflammation caused by stratified contrast-enhancement with wall thickening, is also seen considerably more common in the case of fibrostenosis, which is also an indicator of the chronic phase (10). Macarini et al. (30) found that $9 \%$ of the cases were in the inactive phase, $57 \%$ in the chronic phase, and $34 \%$ in the active phase in their study of 100 patients followed up with CD diagnosis. In our study on 42 patients, a total of 26 intestinal segments consistent with CD were found in 19 patients, and all patients were observed to have a target sign, which is the sign of active inflammation. In addition, $13(68.4 \%)$ of the patients had chronic stage findings in a total of 18 (69.2\%) intestinal segments, and there were findings consistent with activation. However, no case in remission was found which was attributed to 
the low number of cases and the fact that the cases in remission did not present to the outpatient clinic, and this was considered to be the limitation of our study. In the active inflammation phase, the appearance of the target sign is caused by the low signal of the submucosa due to pathological contrast enhancement in the mucosa and serosa; however, the appearance of the target sign in the remission phase is caused by fat accumulation in the submucosa (31). In the light of these findings, the activeremission distinction can be made. One of the limitations of our study is the inability to investigate the significance of the appearance of the target sign in the differentiation of active inflammation and remission due to the absence of intestinal involvement in the remission phase. In our study, in addition to intestinal wall thickening in patients in the active phase, stratified contrast enhancement of the intestinal wall was also detected.

Increased adjacent mesenteric adipose tissue, lymphadenopathy, and the comb sign, which is the hypervascular appearance of the mesenteric adipose tissue, in CD are considered an indicator of transmural inflammation (19). In our study, of 26 involved intestinal segments, increased mesenteric adipose tissue was observed in 16, adjacent mesenteric lymphadenopathy in 14 , and comb sign in 12 .

Active and non-active strictures may be differentiated by evaluating the motility of the intestinal wall on the "cine" coronal image (32). Fibrotic strictures are observed aperistaltically (33). In our study, there was stenosis in the intestinal lumen associated with the chronic stage in a total of 18 intestinal segments in 13 of our patients, and no peristalsis was observed in these segments on coronal "cine" images.

One of the most important advantages of cross-sectional imaging methods is that it can show the extraluminal complications of the disease and pathologies in the mesentery, other intra-abdominal organs, and vascular structures (8). The extraluminal complications observed in our patients include enterovesical fistula, ileosigmoid fistula, and enterocutaneous fistula in one case each. Abdominal pathologies detected in our patients but not associated with CD were hepatomegaly in 1 case, uterine myoma in 1 case, accessory spleen in 1 case, and renal cysts in 2 cases.

The main limitations of our study were the small number of cases and the absence of lesions at different stages. The limitations of the MRE include the consummation of a large amount of liquid in a short time before the procedure, the difficulty of implementation of the technique, the long duration of the procedure, and its expensiveness.

\section{CONCLUSION}

In conclusion, MRE has an important role in the diagnosis and especially in the follow-up of CD due to not containing ionizing radiation, its high tissue contrast, its ability to acquire a real-time and functional image, its ability to reveal intestinal and extraintestinal pathologies in addition to anatomical information in a single examination as it is a cross-sectional imaging method, and the high safety profile of gadolinium administered as an IV contrast medium during the procedure. We believe that MRE is an imaging modality that should be preferred primarily in the diagnosis and follow-up of treatment success of CD, which manifests with terminal-nonterminal ileum and/or jejunal involvement..

Financial disclosures: The authors declared that this study hasn't received no financial support.

Conflict of Interest: The authors declare that they have no competing interest.

Ethical approval: Our study was carried out upon permission no. 24.02.2014/75 dated 24.02.2014 of the Medical Ethics Committee of Gaziantep University, Faculty of Medicine.

\section{REFERENCES}

1. Maglinte D, Kelvin F, O'Connor K, et al. Current status of small bowel radiography. Abdominal imaging. 1996;21:247-57.

2. Lee SS, Kim AY, Yang S-K, et al. Crohn disease of the small bowel: comparison of CT enterography, MR enterography, and small-bowel follow-through as diagnostic techniques. Radiology. 2009;251:751-61.

3. Gökhan I, Korkut M, Tercan M, Bilgen I. İnce Barsak Lezyonlarinin Gösterilmesinde Enteroklizisi. Ege Tıp Dergisi. 40:131-5.

4. Hara AK, Leighton JA, Heigh RI, et al. Crohn disease of the small bowel: preliminary comparison among CT enterography, capsule endoscopy, small-bowel followthrough, and ileoscopy. Radiology. 2006;238:128-34.

5. Lennard-Jones J. Classification of inflammatory bowel disease. Scandinavian J Gastroenterol. 1989;24:2-6.

6. Mekhjian HS, Switz DM, Melnyk CS, et al. Clinical features and natural history of Crohn's disease. Gastroenterology. 1979;77:898-906.

7. Florie J, Wasser MN, Arts-Cieslik K, et al. Dynamic contrast-enhanced MRI of the bowel wall for assessment of disease activity in Crohn's disease. Am J Roentgenol. 2006; 186:1384-92.

8. Sempere GJ, Martinez Sanjuan V, Medina Chulia E, et al. MRI evaluation of inflammatory activity in Crohn's disease. Am J Roentgenol. 2005;184:1829-35.

9. Louis E, Collard A, Oger A, et al. Behaviour of Crohn's disease according to the Vienna classification: changing pattern over the course of the disease. Gut. 2001;49:777-82.

10. Schill G, lesalnieks I, Haimerl M, et al. Assessment of disease behavior in patients with Crohn's disease by MR enterography. Inflammatory Bowel Diseases. 2013;19:98390.

11. Satsangi J, Silverberg M, Vermeire S, Colombel J. The Montreal classification of inflammatory bowel disease: controversies, consensus, and implications. Gut. 2006;55:749-53. 
12. Castiglione F, Mainenti PP, De Palma GD, et al. Noninvasive diagnosis of small bowel Crohn's disease: direct comparison of bowel sonography and magnetic resonance enterography. Inflammatory Bowel Diseases. 2013;19:991-8.

13. Amzallag-Bellenger E, Oudjit A, Ruiz A, et al. Effectiveness of MR enterography for the assessment of smallbowel diseases beyond Crohn disease. Radiographics. 2012;32:1423-44.

14. Neubauer H, Pabst T, Dick A, et al. Small-bowel MRI in children and young adults with Crohn disease: retrospective head-to-head comparison of contrast-enhanced and diffusion-weighted MRI. Pediatric Radiol. 2013;43:103-14.

15. Toma P, Granata C, Magnano G, Barabino A. CT and MRI of paediatric Crohn disease. Pediatric Radiol. 2007;37:108392.

16. Amzallag-Bellenger $\mathrm{E}$, Soyer $\mathrm{P}$, et al. Prospective evaluation of magnetic resonance enterography for the detection of mesenteric small bowel tumours. Eur Radiol. 2013;23:190110.

17. Kuo PH, Kanal E, Abu-Alfa AK, Cowper SE. Gadoliniumbased MR contrast agents and nephrogenic systemic fibrosis. Radiology. 2007;242:647-9.

18. Buisson A, Joubert A, Montoriol PF, Diffusion weighted magnetic resonance imaging for detecting and assessing ileal inflammation in C rohn's disease. Alimentary Pharmacol Therapeutics. 2013;37:537-45.

19. Fidler JL, Guimaraes L, Einstein DM. MR imaging of the small bowel. Radiographics. 2009;29:1811-25.

20. Hidalgo LH, Moreno EA, Arranz JC, et al. Magnetic resonance enterography: review of the technique for the study of Crohn's disease. Radiología (English Edition). 2011;53:42133.

21. Low RN, Sebrechts CP, Politoske DA, et al. Crohn disease with endoscopic correlation: single-shot fast spin-echo and gadolinium-enhanced fat-suppressed spoiled gradientecho MR imaging. Radiology. 2002;222:652-60.

22. Menys A, Atkinson D, Odille F, et al. Quantified terminal ileal motility during MR enterography as a potential biomarker of Crohn's disease activity: a preliminary study. Eur Radiol. 2012;22:2494-501.
23. Rimola J, Rodríguez S, García-Bosch O, Ordás I, Ayala E, Aceituno $M$, et al. Magnetic resonance for assessment of disease activity and severity in ileocolonic Crohn's disease. Gut. 2009;58:1113-20.

24. Goei R, Nix M, Kessels A, Ten Tusscher M. Use of antispasmodic drugs in double contrast barium enema examination: glucagon or buscopan? Clinical radiology. 1995;50:553-7.

25. Pomeroy A, Rand M. Anticholinergic effects and passage through the intestinal wall of Nbutylhyoscine bromide. $J$ Pharmacy Pharmacol. 1969;21:180-7.

26. Ahualli J. The target sign: bowel wall. Radiology. 2005;234:549-50.

27. Onay $M$, Erden $A$, Binboğa $A B$, et al. Assessment of Imaging Features of Crohn's Disease with MR Enterography. Turkis $\mathrm{J}$ Gastroenterol: the Official J Turkish Society Gastroenterol. 2021;32:631-9.

28. Hoeffel C, Crema MD, Belkacem A, et al. Multi-detector row CT: spectrum of diseases involving the ileocecal area. Radiographics. 2006;26:1373-90.

29. Bickelhaupt S, Froehlich J, Cattin R, et al. Differentiation between active and chronic Crohn's disease using MRI small-bowel motility examinations-Initial experience. Clin Radiol. 2013;68:1247-53.

30. Macarini L, Stoppino L, Centola A, et al. Assessment of activity of Crohn's disease of the ileum and large bowel: proposal for a new multiparameter MR enterography score. La Radiologia Medica. 2013;118:181-95.

31. Sinha R, Verma R, Verma S, Rajesh A. MR enterography of Crohn disease: part 2, imaging and pathologic findings. Am J Roentgenol. 2011;197:80-5.

32. Kitazume $\mathrm{Y}$, Satoh $\mathrm{S}, \mathrm{Hosoi} \mathrm{H}$, et al. Cine magnetic resonance imaging evaluation of peristalsis of small bowel with longitudinal ulcer in Crohn disease: preliminary results. $J$ Computer Assisted Tomography. 2007;31:876-83.

33. Rimola J, Planell N, Rodríguez S, et al. Characterization of inflammation and fibrosis in Crohn's disease lesions by magnetic resonance imaging. Am J Gastroenterol. $2015 ; 110: 432$. 